\title{
Enhanced production of flavonoids by methyl jasmonate elicitation in cell suspension culture of Hypericum perforatum
}

\author{
Jing Wang ${ }^{1,2}$, Jie Qian ${ }^{3}$, Lingyun Yao ${ }^{1,2^{*}}$ and Yanhua Lu ${ }^{1,2^{*}}$
}

\begin{abstract}
Background: Flavonoids of Hypericum perforatum are important secondary metabolites which have been widely utilized in medicine for a range of purposes. The use of methyl jasmonate (MeJA) elicitation for the enhancement of flavonoid production in cell suspension culture of H. perforatum would be an efficient alternative method for the flavonoid production.

Results: MeJA influenced the cells growth and flavonoid production. The optimal elicitation strategy was treatment of the cell cultures with $100 \mu \mathrm{mol} / \mathrm{L}$ MeJA on day 15, which resulted in the highest flavonoid production (280 mg/L) and 2.7 times of control cultures. The activities of catalase (CAT) were inhibited after MeJA treatment in the cell cultures, while the activities of phenylalanine ammonia lyase (PAL) increased, which led to the enhancement of flavonoid production.

Conclusion: MeJA elicitation is a useful method for the enhancement of flavonoid production in cell suspension culture of $H$. perforatum.
\end{abstract}

Keywords: MeJA; Hypericum perforatum; Suspension culture; Flavonoids

\section{Background}

Hypericum perforatum, commonly known as St. John's wort, is a perennial herb native to Europe and also a traditional medicinal plant which has been utilized in Chinese folk medicine for a range of purposes [1,2]. The medicinal applications of $H$. perforatum, including skin wounds, eczema, burns, diseases of the alimentary tract, and psychological disorders, have been related to the phenolic composition of the plant, particularly to hypericins, hyperforins, and flavonoids [3,4]. The efficacy of medical constituents of $H$. perforatum is based on the whole secondary metabolites, rather than the presence of single chemical compound [5]. Flavonoids, specifically quercetin and its glycoside derivatives, comprise the major group of biologically active metabolites in $H$. perforatum and are important biochemical markers in authenticating the herbal plant materials $[4,6]$.

\footnotetext{
* Correspondence: Lyyao1982@qq.com; luyanhua@ecust.edu.cn 'State Key Laboratory of Bioreactor Engineering, Department of Bioengineering, East China University of Science and Technology, 130 Meilong Rd., Shanghai 200237, China

Full list of author information is available at the end of the article
}

The consumption of $H$. perforatum-derived products as pharmaceutical preparations or food additives has increased dramatically, and it is presently one of the most consumed medicinal plants in the world $[4,7]$. The extracts of $H$. perforatum currently used in foods and pharmaceutics, mostly composed of flavonoids, are mainly obtained from the top aerial parts collected in the flowering stage $[6,8]$. However, the quality of the flavonoid-rich extracts derived from field-grown plants may be affected by many environmental factors as well as biological processes [5]. Furthermore, field cultivation of $H$. perforatum requires a long growth period and plant management, which is a slow and laborious process [6]. Therefore, an alternative method for more efficient and controllable production of flavonoids from $H$. perforatum is urgently required.

Plant cell, tissue, and organ cultivation technology has been successfully applied to the production of pharmaceutically valuable compounds and other fine chemicals of commercial interest in recent years [9]. For instance, cell suspension cultures of Panax ginseng have been widely used for the production of saponin and other metabolites [10]. Plant-mediated green biomimetic synthesis of silver 
nanoparticle was considered a widely acceptable technology for rapid production of silver nanoparticles for successfully meeting the excessive need and current market demand and resulting in a reduction in the employment or generation of hazardous substances to human health and the environment [11]. Till now, a number of efforts have been made for the establishment of cell and/or adventitious root cultures of $H$. perforatum for the production of hypericins, phenolics, and xanthones [12-15]. The information on the factors affecting biomass and aforementioned metabolites of $H$. perforatum was also investigated through elicitation and culture optimization [1,16-18]. However, there are few reports on the production of flavonoids from cell suspension culture of $H$. perforatum, and little is known about the strategies for hyperproduction of biomass and flavonoids.

Many cell cultures have been established from plants, but they seldom produce sufficient amounts of the required secondary metabolites. Secondary metabolite biosynthesis in plants depends on environmental stresses; their accumulation can be stimulated by precursors and elicitors [19]. Precursors are intermediate compounds of the secondary metabolite biosynthesis cycles, which would be toxic to the culture if not used at an appropriate stage or concentration [20]. Elicitors are biological (components of microbial cells and poly- and oligosaccharides), chemical (heavy metals, pesticides, and the signaling compounds in plant defense responses), or physical (cold shock, UV, hyperosmotic stress, ultrasound, and pulsed electric field) factors that induce enzymatic activity against stress [19-21]. Jasmonic acid (JA) and its methyl ester, methyl jasmonate (MeJA), have been proposed to be important signaling compounds in the process of elicitation leading to the hyperproduction of various secondary metabolites [14]. They have also been reported to play a key role in signal transduction processes that regulate defense responses in plants and shown effective to enhance the production of secondary metabolites in cell cultures $[14,19]$.

In the present study, the effect of MeJA on cell growth and flavonoid biosynthesis in the H. perforatum cell suspension culture was investigated in small batches. Some parameters, such as elicitation time and MeJA concentration, on biomass and flavonoid production were studied in detail. The activities of key enzymes (catalase and phenylalanine ammonia lyase) related to plant stress responses and secondary metabolite biosynthesis were investigated as well. To the best of our knowledge, this is the first report on the induction of flavonoid production by MeJA in cell suspension culture of $H$. perforatum.

\section{Materials and methods Chemicals}

MeJA was supplied by Drug Institute of East China University of Science and Technology (Shanghai, China).
Salicylic acid (SA), ammonium metavanadate $\left(\mathrm{NH}_{4} \mathrm{VO}_{3}\right)$, and nickel sulfate $\left(\mathrm{NiSO}_{4}\right)$ were purchased from Shanghai Zhong Lan Chemical Company (Shanghai, China). Acetonitrile of HPLC grade was purchased from TEDIA Company, USA. All other chemicals (analytical grade) were purchased from Shanghai Chemical Co., Ltd. (Shanghai, China).

\section{Plant material and callus induction}

$H$. perforatum plants were provided by Prof. Jie Qian (Tongji University, China) and were cultivated in the greenhouse. The fresh stem explants of $H$. perforatum were washed thoroughly with tap water, surface-sterilized with $75 \%$ ethanol for $60 \mathrm{~s}$, and then soaked in 10\% sodium hypochlorite solution for $30 \mathrm{~s}$ and rinsed seven times in sterile deionized water. The clean and sterilized stem explants were cut into $5-\mathrm{mm}$ segments and inoculated on solid Murashige and Skoog (MS) [22] medium supplemented with $1.0 \mathrm{mg} / \mathrm{L}$ 2,4-D, $0.2 \mathrm{mg} / \mathrm{L}$ 6-benzyladenine (BA), and $25 \mathrm{~g} / \mathrm{L}$ sucrose to induce callus formation. After 1 month, the successfully induced callus was separated from the explants and cultured separately until used for the establishment of cell suspensions.

\section{Suspension cultures of $\boldsymbol{H}$. perforatum cells}

Cell suspension cultures were initiated from the friable callus and maintained in the liquid MS medium $(\mathrm{pH}$ 5.8) supplemented with $1.0 \mathrm{mg} / \mathrm{L} 2,4-\mathrm{D}, 0.2 \mathrm{mg} / \mathrm{L} 6$ benzyladenine (BA), and $25 \mathrm{~g} / \mathrm{L}$ sucrose. A sterile standard sieve with aperture of $300 \mu \mathrm{m}$ was used to filter the initial established suspension cells to obtain homogeneous cultures. The pre-weighed cells were cultured in a $250-\mathrm{mL}$ Erlenmeyer flask containing a 50-mL medium; cultures were placed on a rotary shaker shaking at $120 \mathrm{rpm}$ at $25 \pm 2^{\circ} \mathrm{C}$ under continuous illumination. Every 20 days, cells were subcultured to fresh media with $5.0-\mathrm{g}$ fresh weight (FW) in $250-\mathrm{mL}$ flasks.

\section{Elicitation of cell suspension culture}

Four elicitors including $\mathrm{MeJA}, \mathrm{SA}, \mathrm{NH}_{4} \mathrm{VO}_{3}$, and $\mathrm{NiSO}_{4}$ were used to study the elicitation effect on flavonoid production by the cell suspension cultures of $H$. perforatum. MeJA and SA were dissolved in ethanol, $\mathrm{NH}_{4} \mathrm{VO}_{3}$ and $\mathrm{NiSO}_{4}$ were dissolved in water, and the four elicitors were filter-sterilized before adding into the suspension cultures. Based on the results of preliminary experiments, the feeding concentration of MeJA, $\mathrm{SA}, \mathrm{NH}_{4} \mathrm{VO}_{3}$, and $\mathrm{NiSO}_{4}$ was 50,100, 50, and $15 \mu \mathrm{M}$, respectively. As a control, filter-sterilized ethanol was added to the cell suspension culture with a final concentration of $0.2 \%$.

According to the results of the above experiments, MeJA was selected for further study. The MeJA induction time and feeding concentration, known to be crucial to plant cell culture, were investigated by single-factor 
experimental design by varying a single factor at a time and keeping other factors at a constant value. All experiments were performed in triplicate, and data are expressed as the mean of three samples with standard deviation.

\section{Extraction and HPLC analysis of secondary metabolites}

$H$. perforatum extracts were prepared by soaking $0.5 \mathrm{~g}$ of the dried cells in $10 \mathrm{~mL}$ of methanol and treated with 1 $h$ of ultrasonic extraction for two times. The extracts were then centrifuged at $10,000 \mathrm{rpm}$ at $4^{\circ} \mathrm{C}$. The supernatant was combined and used for HPLC analysis and flavonoid determination.

The HPLC system of Shimadzu LC-10Avp Plus with a PDA detector (SPD-M20A) and a $\mathrm{C}_{18}$ column $(4.6 \mathrm{~mm} \times$ $250 \mathrm{~mm}, 5 \mu \mathrm{m}$, Eclipse XDB C18) was used for the qualitative and quantitative analyses of flavonoids and other metabolites in the methanol extracts. The mobile phase was acetonitrile (A) and $0.1 \%$ trifluoroacetic acid (B). A gradient method was used for the separation of the extracted samples: 0-25 min, $15 \%-40 \%$ A; $25-40 \mathrm{~min}$, 40\%-100\% A. The elution flow rate and detection wavelength were set at $1.0 \mathrm{~mL} / \mathrm{min}$ and $254 \mathrm{~nm}$, respectively. The identity of peaks separated by HPLC was confirmed by the injection of standard, and UV spectral analysis was carried out to confirm compound identification.

\section{Determination of biomass and flavonoid content}

The plant cell biomass is expressed as the gram fresh cell weight and/or dry cell weight per liter. Cell suspension cultures were filtered and washed by deionized water, then cells were collected and weighed to get the FW. The collected cells were dried in the vacuum drying oven at $45^{\circ} \mathrm{C}$ until constant weight (DW) was attained.

The flavonoid content was assayed using UV colorimetric method as reported elsewhere [5,13]. Briefly, 0.5 $\mathrm{mL}$ of the methanolic plant cell extract was mixed with $2 \mathrm{~mL}$ of distilled water and subsequently with $0.15 \mathrm{~mL}$ of a $5 \% \mathrm{NaNO}_{2}$ solution. After $6 \mathrm{~min}, 0.15 \mathrm{~mL}$ of a $10 \%$ $\mathrm{AlCl}_{3}$ solution was added and the mixture was allowed to stand for a further 6 min before $2 \mathrm{~mL}$ of $4 \% \mathrm{NaOH}$ solution was added. Absorbance of the mixed solution was measured at $510 \mathrm{~nm}$ using a UV-Vis spectrophotometer (UV-1650PC, Shimadzu, Japan). Rutin was used as standard compound for the quantification of total flavonoid. Results were expressed as milligram of rutin equivalents per gram of dry cells. Data were expressed as means \pm SD for three replications.

\section{Enzyme activity analysis}

Suspension culture cells were harvested for evaluation of the catalase (CAT) activity level as described by Georgiew et al [23]. The decomposition of $\mathrm{H}_{2} \mathrm{O}_{2}$ was followed by measuring the decrease in absorbance at $240 \mathrm{~nm}$. One unit of CAT is the amount that decomposes $1 \mu \mathrm{mol}$ of
$\mathrm{H}_{2} \mathrm{O}_{2}$ for 1 min at $\mathrm{pH} 7.0$ and $25^{\circ} \mathrm{C}$. Protein was estimated by the procedure of Lowry et al. [24], using crystalline bovine albumin as standard. Phenylalanine ammonia lyase (PAL) was extracted from fresh $H$. perforatum cells with borate buffer $(\mathrm{pH} 8.8)$. The cells were ground in the buffer $(0.15 \mathrm{~g} / \mathrm{mL})$ for 2 min with a pestle and mortar on ice and then centrifuged at $10,000 \mathrm{rpm}$ and $4^{\circ} \mathrm{C}$ for $20 \mathrm{~min}$ to obtain a solid-free extract. The PAL activity was determined based on the conversion of L-phenylalanine to cinnamic acid as described by Wu and Lin [21].

\section{Results and discussion}

\section{Callus induction and cell suspension culture establishment}

In the preliminary work, calyx, leaf, petal, and stem segments of $H$. perforatum were used as explants for callus induction. It revealed that callus induction was significantly affected by the type of explants and the stem was the best explant for the initiation of a friable callus (Figure 1A,B,C). The stem-derived callus was incubated at $25 \pm 2^{\circ} \mathrm{C}$ under continuous illumination on a solid MS medium and subcultured every 4 weeks. Cell suspension culture was initiated once the stable cell lines were obtained on the solid MS medium. Given the potential for deriving useful secondary metabolites from plant resource, cell suspension cultures of $H$. perforatum were established to produce hypericin, naphtodianthrones, and phenylpropanoids $[12,14,18]$. In addition, some efforts have been made for the establishment of adventitious root cultures of $H$. perforatum for the production of flavonoids, phenolics, and xanthones [5,15-17]. In the present study, cell suspension culture was successfully established (Figure 1D) from the stem-derived calli of $H$. perforatum for further investigation of flavonoids' production performance.

To understand the growth and flavonoid accumulation in $H$. perforatum cells for determining the optimal cultivation time, cultures were analyzed throughout a 30-day period (Figure 2A). The cell growth exhibited a lag phase or slow growth period in the first 10 days; subsequently, the cells entered their exponential growth phase with the maximum DW of $8.2 \mathrm{~g} / \mathrm{L}$ reached on day 20 . As shown in Figure 2B, the flavonoid production is related to cell growth and its content reached maximum with a value of $16 \mathrm{mg} / \mathrm{g}$ DW during stationary or declining phase between day 20-25. The content of total flavonoids in cell suspension culture of $H$. perforatum (16 mg/g DW) was lower than that of the adventitious root cultures (42.7 $\mathrm{mg} / \mathrm{g}$ DW) as reported earlier [5]. However, the culture period for the suspension cells of $H$. perforatum (3 weeks) was much shorter than that of the adventitious root cultures (6 weeks). In addition, the flavonoid production in cell suspension culture of $H$. perforatum can be further improved by the supplementation of effective elicitors 


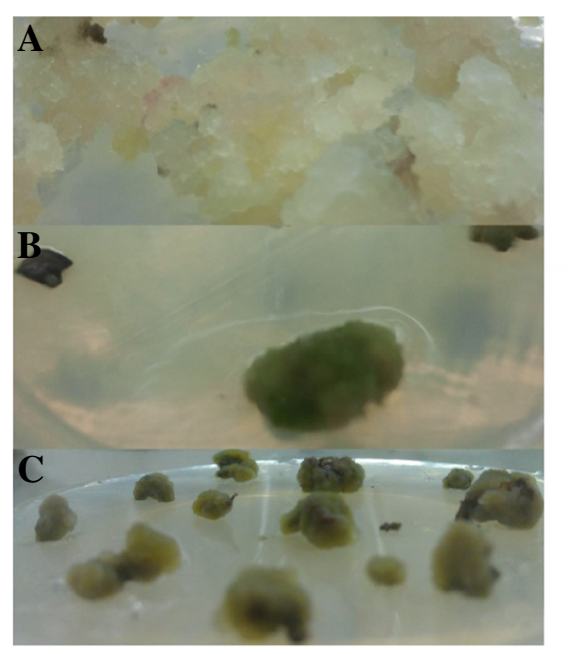

D

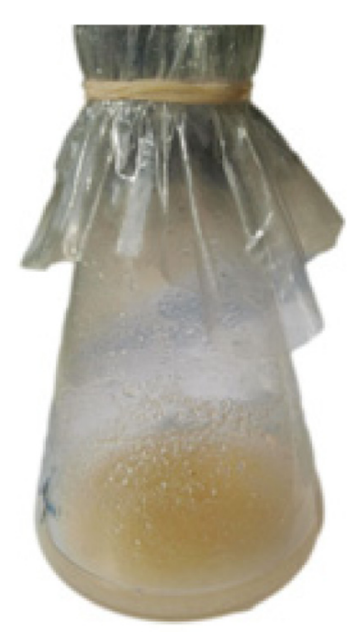

Figure 1 Callus induced from different explants of $H$. perforatum and established cell suspension cultures. (A) Callus induced from stem explants; (B) callus induced from leaf explants; (C) callus induced from calyx explants; (D) cell suspension culture.

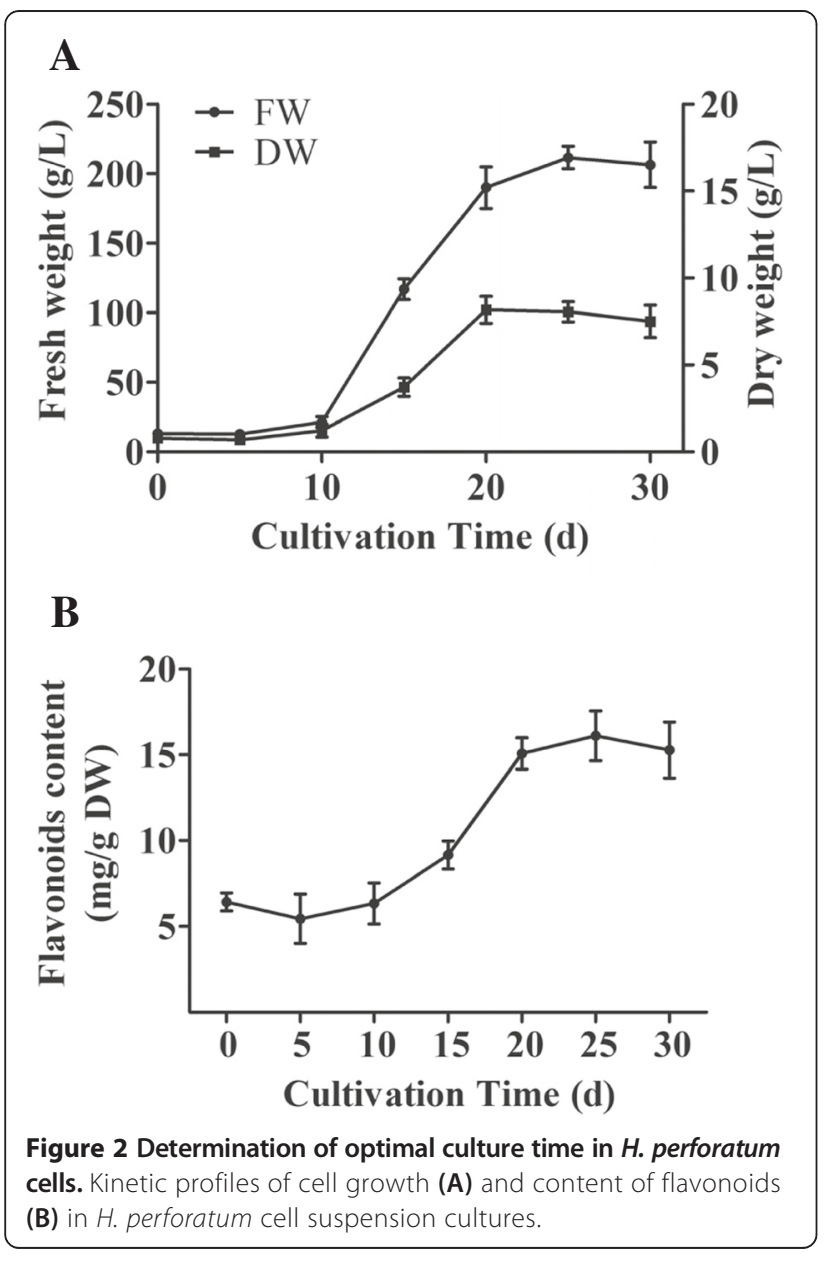

$[18,19]$. Therefore, it is crucial to screen potential elicitors for the hyperproduction of flavonoids in a shortened culture period by cell suspension culture of $H$. perforatum.

HPLC was used to recognize the flavonoids biosynthesized in the cell cultures on the basis of the retention times and UV spectras with those of reference standards. As shown in Figure 3A,B,C,D, hyperin and quercetin were the main flavonoids obtained from the established cell suspension cultures, which was in accordance with a previous study [6]. In addition, the medium was examined, and no flavonoids were detected.

\section{Selection of MeJA as the elicitor in cell suspension culture of $H$. perforatum}

Some known abiotic elicitors for plant secondary metabolites such as signaling molecules (MeJA and SA) and inorganic salts $\left(\mathrm{NH}_{4} \mathrm{VO}_{3}\right.$ and $\left.\mathrm{NiSO}_{4}\right)$ were tested for their effect on cell growth and flavonoid production by the $H$. perforatum cell suspension culture. Four treatments, MeJA $(50 \mu \mathrm{M})$, salicylic acid $(100 \mu \mathrm{M}), \mathrm{NH}_{4} \mathrm{VO}_{3}$ $(50 \mu \mathrm{M})$, and $\mathrm{NiSO}_{4}(15 \mu \mathrm{M})$ were applied to the cell cultures on day 15 based on our previous lab results. As shown in Figure 4, the growth of cell cultures was inhibited by the addition of the four elicitors as compared to the control cultures. Similar findings were also observed by Dong and Zhong [25], in which the application of elicitation in suspension cell culture severely inhibited the growth of Taxus chinensis cells. However, elicitation treatments may have varied effects on different cell lines. Some researchers have reported that the growth of cell cultures was not affected by elicitors [26]. The effects of the elicitors on flavonoid production are also given in Figure 4. Flavonoid content was promoted by MeJA and 
<smiles>O=c1c(O)c(-c2ccc(O)c(O)c2)oc2cc(O)cc(O)c12</smiles>

Hyperin<smiles></smiles>

Quercetin

B

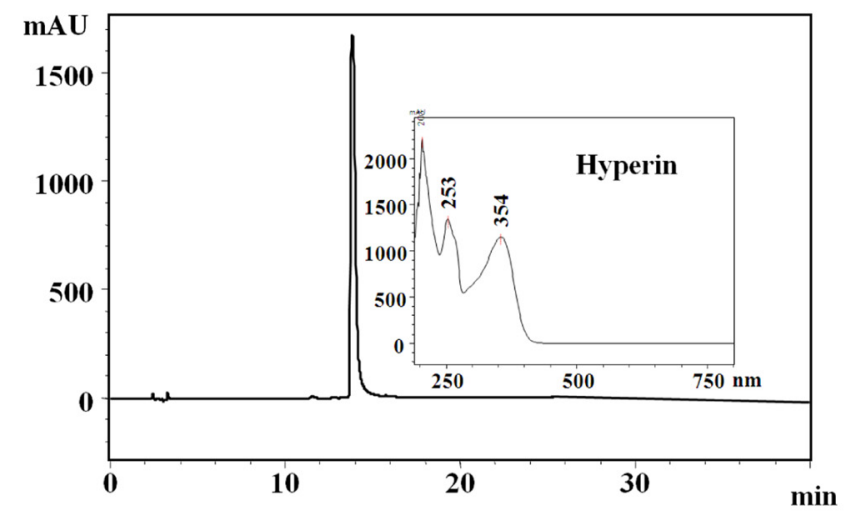

C

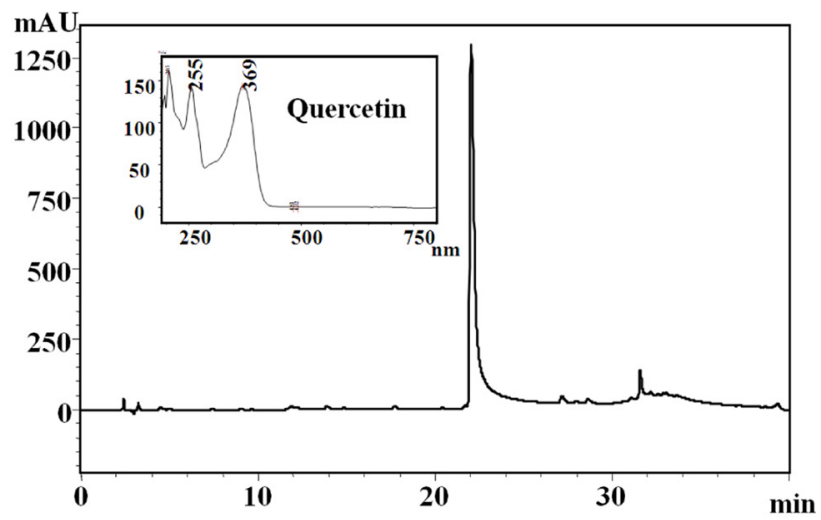

D

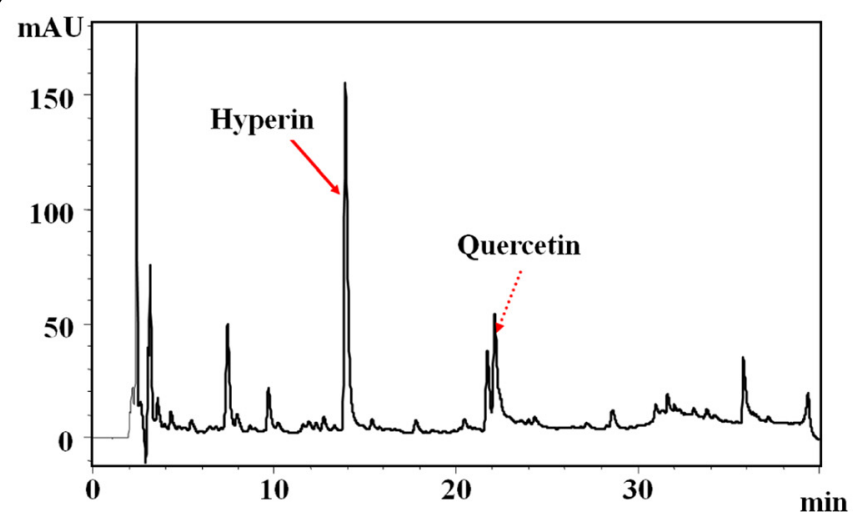

Figure 3 Hyperin and quercetin obtained from the established cell suspension cultures. Chemical structures of hyperin and quercetin (A) and chromatographic profile of hyperin (B), quercetin (C) and the suspension cell extracts (D). The two insets are the UV spectrums of standard hyperin (B) and quercetin (C). 


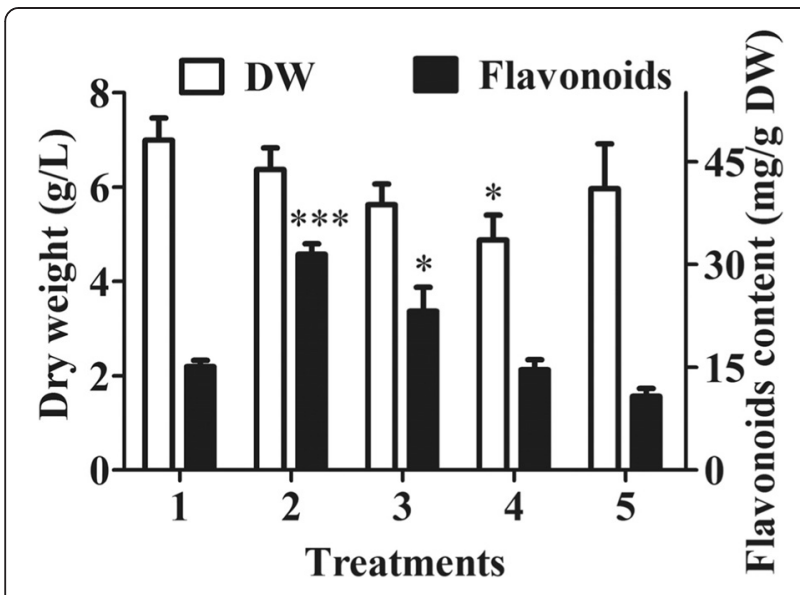

Figure 4 The effects of four abiotic elicitors on $\mathrm{H}$. perforatum cell growth and flavonoid accumulation. 1 Control; $2 \mathrm{MeJA}$; $3 \mathrm{SA}$; $4 \mathrm{NH}_{4} \mathrm{VO}_{3} ; 5 \mathrm{NiSO}_{4}\left({ }^{*} P<0.05,{ }^{* *} P<0.01\right.$, and ${ }^{* * *} P<0.001$ indicate statistical significance compared to the control).

SA induction, which were 2.1 and 1.5 times higher in comparison to control cultures (15.36 mg/g DW), respectively. Several studies on other plant cell cultures have shown that MeJA and SA elicitation can enhance the production of secondary metabolites. For instance, MeJA was recognized as an effective elicitor that could increase the production of paclitaxel in Taxus candensis and T. cuspidate [27], anthocyanin in Tulipa gesneriana [28], and gymnemic acid in Gymnema sylvestre [29]. In SA-elicited cell suspension culture of $H$. perforatum, the production of both hypericin and pseudohypericin has doubled as compared to control cell suspension cultures [18]. As shown in Figure 4, MeJA and SA both induced flavonoid accumulation in $H$. perforatum cell suspension cultures, but SA was less efficient than MeJA in promoting flavonoid accumulation under the tested feeding concentration.

Some literatures reported the enhancement of metabolite production by $\mathrm{NH}_{4} \mathrm{VO}_{3}$ and $\mathrm{NiSO}_{4}$ elicitation [30]. However, the two elicitors revealed negative effects on biomass and flavonoid accumulation in $H$. perforatum cell cultures (Figure 4). It was probably due to the significant biological toxicity caused by the inorganic salts [30]. Some other elicitors such as fluoro- and hydroxylcontaining derivatives of methyl jasmonate, which were proven more potent than methyl jasmonate in suspension culture of Taxus [31,32], may also serve as possible options for the enhancement of flavonoid biosynthesis in $H$. perforatum. In addition, some new elicitors have been reported to have significantly promoted secondary metabolite biosynthesis by plant cell cultures [33]. However, elicitation treatments may have varied effects among different cell lines as mentioned above. Therefore, efforts devoted into the enhancement of flavonoid production by $H$. perforatum cell suspension culture are still required considering its further application. In the present investigation, the addition of MeJA $(50 \mu \mathrm{M})$ resulted in maximum flavonoid production, which indicated the potential of this abiotic elicitor for the enhancement of flavonoid biosynthesis in cell suspension culture of $H$. perforatum and was selected for further study.

\section{Effects of MeJA feeding time on cell growth and flavonoid production}

The elicitor induction time is one of the key factors that affect the cell growth and product yield for plant cell suspension culture [33]. The effects of MeJA addition time on cell growth and flavonoid accumulation was evaluated by the addition of $50 \mu \mathrm{M}$ MeJA into the cell cultures on lag phase (day 5 and day 10) and exponential phase (day 15 and day 20). Figure 5A,B,C showed the biomass and flavonoid production of $H$. perforatum cell cultures after MeJA addition. As shown in Figure 5A,B, $\mathrm{C}$, the cell growth and production of flavonoids were suppressed deleteriously when MeJA was added on the lag phase. MeJA treatment on the exponential phase (day 15 and day 20) led to a slow decrease in DW (19.0\% and 9.7\%, respectively); however, the flavonoid content and production were significantly increased as compared to control cultures (Figure 5A,B,C). A similar phenomenon was also observed by Huang and Zhong [30], in which elicitation treatment on the log phase of $P$. ginseng reduced the DW and enhanced ginsenoside accumulation. Notably, MeJA treatment on day 15 resulted in the highest value of flavonoid content (38.26 $\mathrm{mg} / \mathrm{g} \mathrm{DW})$ or production $(229.79 \mathrm{mg} / \mathrm{L})$. Therefore, MeJA treatment on day 15 was taken as the optimal addition time for flavonoid production.

\section{Effects of MeJA dosage on cell growth and flavonoid production}

A suitable elicitor concentration is important for the cell growth and product yield in plant cell suspension culture process [34]. To study the effects of MeJA addition concentrations, cell suspension cultures of $H$. perforatum were treated with different levels (50-200 $\mu \mathrm{M})$ of MeJA after 15 days of cultivation. The DW and flavonoid content on day 20 were shown in Figure 6A. It is clear that all the tested concentrations of MeJA had an inhibitory impact on the cell growth; similar results were also obtained in the SA-induced cell suspension culture of $H$. perforatum [18]. Induction with 50 or $100 \mu \mathrm{M}$ of MeJA decreased DW by $11.9 \%-23.1 \%$, while higher concentration of MeJA $(150 \mu \mathrm{M})$ severely decreased the DW from $7.0 \pm 0.5 \mathrm{~g} / \mathrm{L}$ (control cultures) to $5.0 \pm 0.5 \mathrm{~g} / \mathrm{L}$. Addition of low dosage $(<150 \mu \mathrm{M})$ of MeJA elicitor to the cultured cells of $H$. perforatum increased the flavonoid accumulation. As shown in Figure 6A, the flavonoid content was increased about 1.1-fold with a dosage of $50 \mu \mathrm{M}$ and 

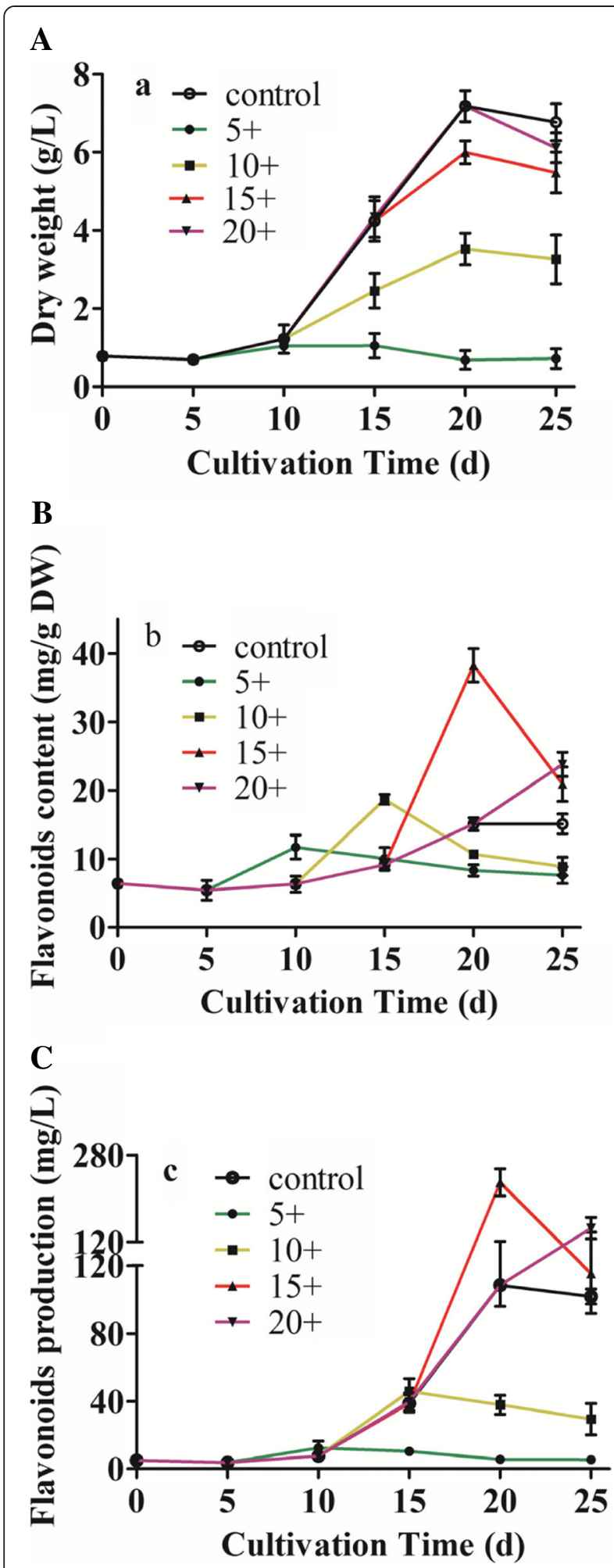

Figure 5 Effects of MeJA $(50 \mu \mathrm{M})$ feeding time on cell growth (A), flavonoid content (B), and flavonoid production (C). 5+, 10+, 15+, and 20+ indicate MeJA feeding on day 5, 10, 15, and 20.

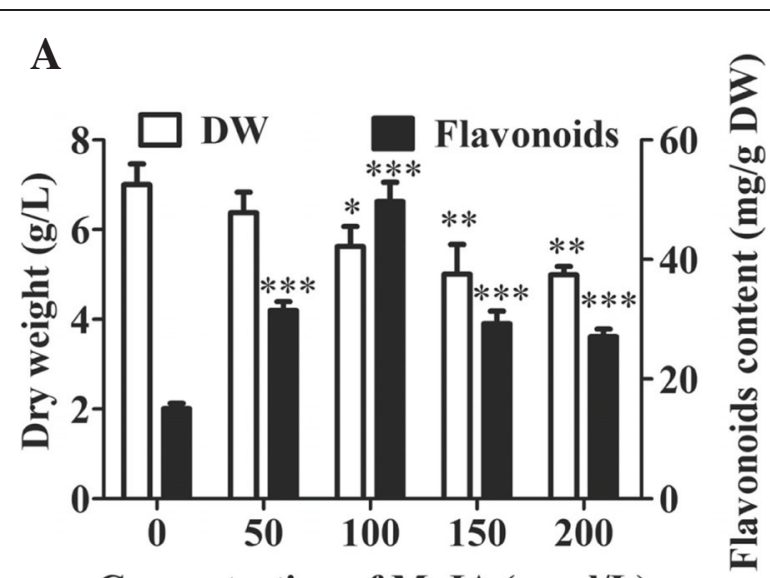

Concentration of MeJA $(\mu \mathrm{mol} / \mathrm{L})$

B

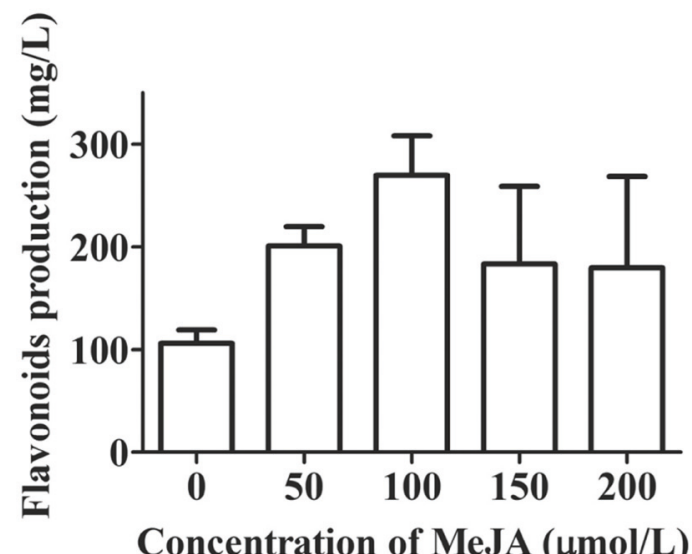

Figure 6 Effects of MeJA dosage on cell growth and flavonoid content (A) and flavonoid production (B). ${ }^{*} P<0.05,{ }^{*} P<0.01$, and ${ }^{* *} P<0.001$ indicate statistical significance compared to the control.

about 2.3-fold with a dosage of $100 \mu \mathrm{M}$ as compared to the control cultures. The flavonoid content reached maximum $(52.8 \mathrm{mg} / \mathrm{g} \mathrm{DW})$ at the elicitation dose of $100 \mu \mathrm{M}$, which was relatively higher than the previously reported values in the adventitious root culture (i.e., 42.7 and 48.6 $\mathrm{mg} / \mathrm{g} \mathrm{DW})[5,17]$. However, further dosage increase (150$200 \mu \mathrm{M})$ decreased the flavonoid biosynthesis compared to moderate MeJA levels (50-100 $\mu \mathrm{M})$. Sensitivity of suspension cell cultures to elicitor concentration differs with plant species $[19,29]$. The negative effect of MeJA at higher concentrations $(200 \mu \mathrm{M})$ on cell growth and metabolite production was also reported in Gymnema sylvestre cell suspension cultures [29]. The best dose of the elicitor with maximum production $(279.5 \mathrm{mg} / \mathrm{L})$ of flavonoids was $100 \mu \mathrm{M}$ as shown in Figure 6B, which was about 2.7 -fold the value of control cultures. The above-mentioned results indicate that the optimal MeJA elicitation strategy was treatment on day 15 with a dosage of $100 \mu \mathrm{M}$. 


\section{Effects of MeJA addition on CAT and PAL activities}

The enzyme activity changes were often related to the secondary metabolite accumulation [35]. For a better understanding of the elicitation effect of MeJA, the activities of two important enzymes (CAT and PAL) under MeJA treatment were determined. Reactive oxygen species (ROS) are toxic intermediates resulting from successive steps in the reduction of molecular $\mathrm{O}_{2}$ in plant cells. The ROS exerts various effects on plant defense responses, including cell wall reinforcement, hypersensitive cell death, defensive gene activation, as well as defensive compound induction [36]. CAT is a well-known intracellular enzyme which protects against the ROS generated within cells [37]. As shown in Figure 7A, the enzyme activity increased with the cultivation time and reached maximum on day 19, thereafter decreased. MeJA downregulated the CAT activity after its addition to the cell cultures on day 15 and kept at a relatively lower level as compared to the control (Figure 7A), which led to a higher

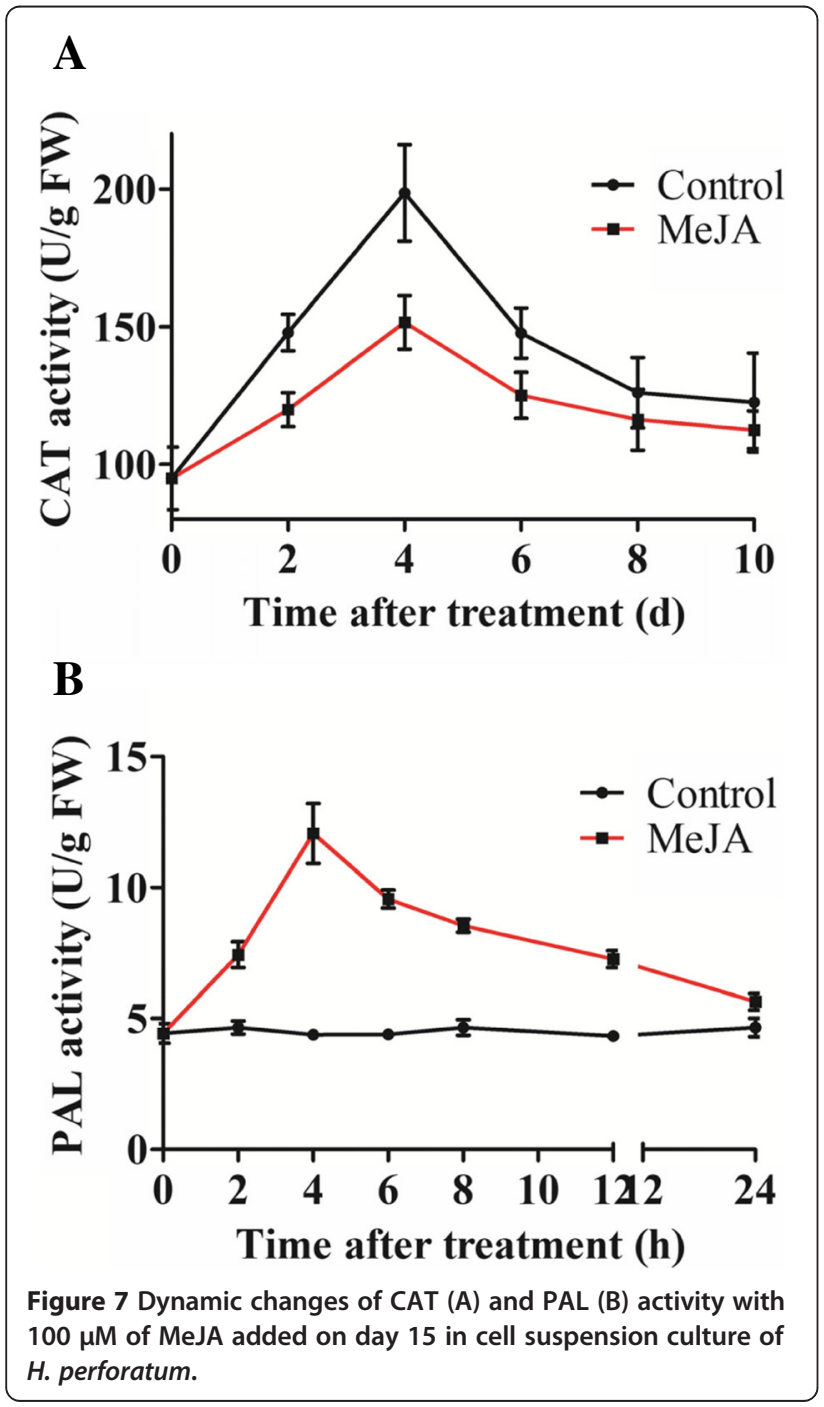

accumulation of ROS and resulted in a promotion of secondary metabolites production. Similar results were observed on phytoalexin production in the suspension cell culture of Glycine max, which indicated that the ROS mediated elicitor-induced accumulation of secondary metabolites [38].

PAL is the first enzyme of phenylpropanoid biosynthesis in plants and plays an important role in the biosynthesis of flavonoids, lignins, and many other compounds [36]. An increase in PAL activity after elicitor treatment often results in enhanced secondary metabolism in plant cells [19]. Figure 7B shows the changes of intracellular PAL activity in the suspension cultures after the treatment by MeJA $(100 \mu \mathrm{M})$. As shown in Figure 7B, MeJA induced the increase of PAL activities and reached maximum (12.1 U/g FW) 4 days after treatment, thereafter decreased. However, cell cultures without MeJA treatment (control) revealed little change of PAL activities. In the presence of MeJA, PAL activity was much higher than that of control (Figure 7B), the elicitor-induced up-regulation of the PAL activity resulted in an improved flavonoid production in the suspension cultures (Figure 6B). Zhao et al. [19] have observed similar results in Salvia miltiorrhiza cell cultures, which indicated that both biotic and abiotic elicitation treatment resulted in the up-regulation of PAL activity and improved tanshinone accumulation as compared to the control cultures. These results demonstrated that MeJA is an efficient elicitor for the induction of flavonoid production in the suspension cell culture of $H$. perforatum.

\section{Conclusions}

Plant cell suspension culture is an efficient alternative method for the production of useful biochemicals. In this work, MeJA-elicited cell suspension cultures of $H$. perforatum enhanced the production of flavonoids through the down-regulation of the CAT activity and up-regulation of the PAL activity. The flavonoid production reached 280 $\mathrm{mg} / \mathrm{L}$ after the optimal elicitation conditions, which was 2.7-fold of the control cultures. These results would be useful for the hyperproduction of flavonoids from $H$. perforatum and would be useful for the production of valuable compounds from other plant cell cultures.

\section{Abbreviations}

CAT: Catalase; DW: Dry cell weight; FW: Fresh cell weight; MeJA: Methyl jasmonate; PAL: Phenylalanine ammonia lyase; SA: Salicylic acid.

Competing interests

The authors declare that they have no competing interests.

Authors' contributions

$J W$ was in charge of the experiments and paper writing. LY Y participated in the experiments and paper writing. J Q kindly offered experimental plant and guided the experiments. YH L directed the study as the tutor. All authors read and approved the final manuscript. 


\section{Acknowledgements}

This work was supported by the National Special Fund for State Key Laboratory of Bioreactor Engineering (2060204) and the Fundamental Research Funds for the Central Universities (WF1113010).

\section{Author details}

${ }^{1}$ State Key Laboratory of Bioreactor Engineering, Department of Bioengineering, East China University of Science and Technology, 130 Meilong Rd., Shanghai 200237, China. ${ }^{2}$ Shanghai Collaborative Innovation Center for Biomanufacturing Technology, 130 Meilong Road, Shanghai 200237, People's Republic of China. ${ }^{3}$ School of Life Science and Technology, Tongji University, Shanghai 200092, China.

Received: 18 November 2014 Accepted: 22 December 2014 Published online: 18 February 2015

\section{References}

1. Wu SQ, Yu XK, Lian ML, Park SY, Piao XC (2014) Several factors affecting hypericin production of Hypericum perforatum during adventitious root culture in airlift bioreactors. Acta Physiol Plant 36:975-981

2. Zou Y, Lu Y, Wei D (2004) Antioxidant activity of a flavonoid-rich extract of Hypericum perforatum L. in vitro. J Agric Food Chem 52:5032-5039

3. Cui XH, Murthy HN, Wu CH, Paek KY (2010) Adventitious root suspension cultures of Hypericum perforatum: effect of nitrogen source on production of biomass and secondary metabolites. In Vitro Cell De-PI 46:3728-3741

4. Saddige Z, Naeem I, Maimoona A (2010) A review of the antibacterial activity of Hypericum perforatum L. J Ethnopharmacol 131:511-521

5. Cui XH, Murthy HN, Jin YX, Yim YH, Kim JY, Paek KY (2011) Production of adventitious root biomass and secondary metabolites of Hypericum perforatum L. in a balloon type airlift reactor. Bioresour Technol 102:10072-10079

6. Bagdonaitè E, Mártonfi P, Repčák M, Labokas J (2012) Variation in concentrations of major bioactive compounds in Hypericum perforatum L. from Lithuania. Ind Crops Prod 35:302-308

7. Savio LEB, Astarita LV, Santarém ER (2011) Secondary metabolism in micropropagated Hypericum perforatum L. grown in non-aerated liquid medium. Plant Cell Tiss Org 108:465-472

8. Zou YP, Lu YH, Wei DZ (2010) Protective effects of a flavonoid-rich extract of Hypericum perforatum L. against hydrogen peroxide-induced apoptosis in PC12 cells. Phytother Res 24:6-10

9. Baque MA, Moh SH, Lee EJ, Zhong JJ, Paek KY (2012) Production of biomass and useful compounds from adventitious roots of high-value added medicinal plants using bioreactor. Biotechnol Adv 30:1255-1264

10. Wu J, Zhong JJ (1999) Production of ginseng and its bioactive components in plant cell culture: current technological and applied aspects. J Biotechnol 68:89-99

11. Priya B, Mantosh S, Aniruddha M (2014) Leaf extract mediated green synthesis of silver nanoparticles from widely available Indian plants: synthesis, characterization, antimicrobial property and toxicity analysis. Bioresour Bioprocess 1:3

12. Xu M, Yang B, Dong J, Lu D, Jin H, Sun L, Xu X (2011) Enhancing hypericin production of Hypericum perforatum cell suspension culture by ozone exposure. Biotechnol Prog 27:1101-1116

13. Cui XH, Chakrabarty D, Lee EJ, Paek KY (2010) Production of adventitious roots and secondary metabolites by Hypericum perforatum $\mathrm{L}$. in a bioreactor. Bioresour Technol 101:4708-4716

14. Walker TS, Pal Bais H, Vivanco JM (2002) Jasmonic acid-induced hypericin production in cell suspension cultures of Hypericum perforatum L. (St. John's wort). Phytochemistry 60:289-293

15. Tocci N, D'Auria FD, Simonetti G, Panella S, Palamara AT, Pasqua G (2012) A three-step culture system to increase the xanthone production and antifungal activity of Hypericum perforatum subsp. angustifolium in vitro roots. Plant Physiol Biochem 57:54-58

16. Tocci N, Simonetti G, D'Auria FD, Panella S, Palamara AT, Valletta A, Pasqua G (2011) Root cultures of Hypericum perforatum subsp. angustifolium elicited with chitosan and production of xanthone-rich extracts with antifungal activity. Appl Microbiol Biotechnol 91:977-987

17. Cui XH, Murthy HN, Paek KY (2014) Pilot-scale culture of Hypericum Perforatum $\mathrm{L}$. adventitious roots in airlift bioreactors for the production of bioactive compounds. Appl Biochem Biotechnol 14:1123-1128

18. Gadzovska S, Maury S, Delaunay A, Spasenoski M, Hagège D, Courtois D, Joseph C (2012) The influence of salicylic acid elicitation of shoots, callus, and cell suspension cultures on production of naphtodianthrones and phenylpropanoids in Hypericum perforatum L. Plant Cell Tiss Org 113:25-39

19. Zhao JL, Zhou LG, Wu JY (2010) Effects of biotic and abiotic elicitors on cell growth and tanshinone accumulation in Salvia miltiorrhiza cell cultures. Appl Microbiol Biotechnol 87:137-144

20. Gueven A, Knorr D (2011) Isoflavonoid production by soy plant callus suspension culture. J Food Eng 103:237-243

21. Lin L, Wu J (2002) Enhancement of shikonin production in single- and two-phase suspension cultures of Lithospermum erythrorhizon cells using low-energy ultrasound. Biotechnol Bioeng 5:78-81

22. Murashige T, Skoog F (1962) A revised medium for rapid growth and bio assays with tobacco tissue cultures. Physiol Plant 15:473-485

23. Georgiev M, Abrashev R, Krumova E, Demirevska K, llieva M, Angelova M (2009) Rosmarinic acid and antioxidant enzyme activities in Lavandula vera MM cell suspension culture: a comparative study. Appl Biochem Biotechnol 159:415-423

24. Lowry OH, Rosebrough NJ, Farr AL, Randall RJ (1951) Protein measurement with the Folin phenol reagent. J Biol Chem 193:265-271

25. Dong HD, Zhong JJ (2001) Significant improvement of taxane production in suspension cultures of Taxus chinensis by combining elicitation with sucrose feed. Biochem Eng J 8:145-162

26. Cai Z, Riedel H, Saw NMMT, Mewis I, Reineke K, Knorr D, Smetanska I (2011) Effects of elicitors and high hydrostatic pressure on secondary metabolism of Vitis vinifera suspension culture. Process Biochem 46:1411-1422

27. Ketchum RE, Tandon M, Gibson DM, Begley T, Shuler M (1999) Isolation of labeled 9-dihydrobaccatin III and related taxoids from cell cultures of Taxus canadensis elicited with methyl jasmonate. J Nat Prod 62:1395-1406

28. Saniewski M, Miszczak A, Kawa-Miszczak L, Wegrzynowicz-Lesiak E, Miyamoto K, Ueda J (1998) Effects of methyl jasmonate on anthocyanin accumulation, ethylene production, and $\mathrm{CO}_{2}$ evolution in uncooled and cooled tulip bulbs. J Plant Growth Regul 17:33-42

29. Veerashree $V$, Anuradha C, Kumar V (2012) Elicitor-enhanced production of gymnemic acid in cell suspension cultures of Gymnema sylvestre R. Br. Plant Cell Tiss Org 108:27-33

30. Huang C, Zhong JJ (2013) Elicitation of ginsenoside biosynthesis in cell cultures of Panax ginseng by vanadate. Process Biochem 48:1227-1245

31. Qian ZG, Zhao ZJ, Xu YF, Qian XH, Zhong JJ (2005) A novel synthetic fluoro-containing jasmonate derivative acts as a chemical inducing signal for plant secondary metabolism. Appl Microbiol Biotechnol 68:98-103

32. Qian ZG, Zhao ZJ, Xu YF, Qian XH, Zhong JJ (2004) Novel chemically synthesized hydroxyl-containing jasmonates as powerful inducing signals for plant secondary metabolism. Biotechnol Bioeng 86:809-816

33. Huang C, Zhong JJ (2013) Enhancement of ginsenoside biosynthesis in cell cultures of Panax ginseng by N,N'-dicyclohexylcarbodiimide elicitation. J Biotechnol 165:30-36

34. Vasconsuelo A, Boland R (2007) Molecular aspects of the early stages of elicitation of secondary metabolites in plants. Plant Sci 172:861-877

35. Xu C, Zhao B, Ou Y, Wang X, Yuan X, Wang Y (2006) Elicitor-enhanced syringin production in suspension cultures of Saussurea medusa. World J Microb Biotechnol 23:965-979

36. Zhao J, Davis LC, Verpoorte R (2005) Elicitor signal transduction leading to production of plant secondary metabolites. Biotechnol Adv 23:283-294

37. Kim YH, Kim Y, Cho E, Kwak S, Kwon S, Bae J, Huh GH (2004) Alterations in intracellular and extracellular activities of antioxidant enzymes during suspension culture of sweetpotato. Phytochemistry 65:2471-2484

38. Guo ZJ, Lamb C, Dixon RA (1998) Potentiation of the oxidative burst and isoflavonoid phytoalexin accumulation by serine protease inhibitors. Plant Physiol 118:1487-1495 